\title{
GLOBAL SHIFT: MAPPING DIFFERENT APPROACHES
}

\author{
Can BIYIK ${ }^{1, *}$ \\ ${ }^{1}$ Department of Civil Engineering, Faculty of Engineering and Natural Sciences, Ankara Y1ldırım Beyazıt University, \\ Ankara, Turkey
}

\begin{abstract}
There is a growing concern as the status quo in developing countries for the urban environment is unsustainable. This paper, therefore, aims to set out a number of future transport visions (in which the long version of the scenario narratives is characteristically formed before the generic images) for the year 2035 which bring about a step change in the level of sustainable transport systems through hypothetical developing urban areas. The objective of this paper shows that it is possible to achieve radical changes and desired targets by aspirational thinking about the future, planning, effort and all demands. This paper firstly provides an overview of urban transport issues, practices, and initiatives for thirty of the world's major emerging economies countries that have recently experienced great changes in urban structure, infrastructure, motorization, and related environmental, economic, and social influences in desirable or undesirable senses. The thirty countries involved in this paper do not have a catchy acronym, but they do share a variety of features. They all have large and relatively young populations; large cities (including megacities) and/or current trends in rapid urbanization; (c) fast rising economies; and (d) huge levels of urban transport-related externalities such as air pollution, road accidents and traffic congestion. The Avoid-Shift-Improve (AS-I) approaches have been generated by a process of the worldwide transport planning review, previous sustainable design works, and extensive discussions with the transport planners, experts, policymakers through a worldwide comprehensive survey before computer-based software was used to create images of a range of developing urban street scenes (or archetypes) in 2020. Then, the paper illustrates virtually how prospective sustainable transportation systems might be integrated into existing urban environments, and the most distinguished transportation paradigms have managed the implementation of suggested striking sustainable transportation solutions in major developing countries. Several international policymakers were provided with samples of generic illustrations in the context of A-S-I approaches. This paper provides a practical recommendation of policy actions and strategies that can be presented in many influential developing countries in the Latin America, Africa, Middle East, Asia and the Pacific region, which would lead to the development of future global sustainable transport systems. It finally points out that such visions need a considerable degree of consensus and radical approaches to tackling them.
\end{abstract}

Keywords: Sustainable transport; Emerging economies; Policy actions

\section{BACKGROUND}

Sustainable transport (in most cases, identified as walking, cycling, and public transport) are extensively endorsed as viable solutions to alleviating some of the well-documented issues associated with cardependent societies. Many national and local governments and various civil society organizations around the developed countries successfully build up transport visions to achieve their sustainable action plans [1-2]. However, there is only a limited understanding of future change in relation to journeys where walking, cycling and public transport could provide a viable travel mode choice to private cars [3-6].

Although the future driving force of the world economy is shifting to a new set of fast-growing emerging countries [7], there is a growing concern as the status quo for the urban environment is unsustainable [8]. A recent systematic literature review pointed out that although transport challenges in nature require for unique cares, all developing countries virtually experience mainly the same urbanisation problems including enormously congested roads; rapidly increasing car and motorcycle ownership and inadequate roadway accommodations for buses and non-motorized transport [9-14]. Pojani and Stead [15] highlighted that the most influential thirty emerging countries involved do not have a catchy

*Corresponding Author: cbiyik@ybu.edu.tr

Received: 31.10.2019 Published: 31.03.2020 
acronym, but they do share a variety of features. Therefore, this paper investigates an overview of urban transport trends, challenges, and practices for thirty of the world's most influential emerging economies - Algeria, Argentina, Bangladesh, Brazil, China, Colombia, Egypt, India, Indonesia, Iraq, Iran, Kuwait, Malaysia, Mexico, Morocco, Nigeria, Pakistan, Peru, Philippines, Russia, Saudi Arabia, South Africa, Taiwan, Thailand, Turkey, Qatar, Ukraine, United Arab Emirates, Venezuela and Vietnam - countries with large economies that have experienced great changes in urban structure, infrastructure, motorization, and related environmental, economic, and social influences over the last few decades.

There is no magic bullet or one clarification and a lot of the national instruments which could be measured, and which are potentially helpful may be extensively unpopular and may have consequences in terms of influences on the development of sustainable urban transport. This paper gives an attempt to properly demonstrate future urban sustainable transport strategies for several selected fastest growing cities by constructing national policy suggestions. It is vital to think again how we think about the future and move away from a dependence on the existing traditional techniques to more inspirational approaches [16-19]. Considering this phenomenon, the objective of this paper recommends global policy and strategies to achieve radical changes and desired targets by aspirational thinking about the future, planning, effort and all demands.

The remaining of this paper is structured as follows. Section 2 presents the general features of urbanization and economic trends of the most influential thirty emerging economies, respectively. Then, it attempts to demonstrate the most influential thirty emerging countries involved do not have a catchy acronym, but they do share a similar variety of urban transport challenges. Section 3 demonstrates the general framework for the classification of A-S-I transport development technique. Section 4 suggests a number of future transport visions, which bring about a step change in the level of sustainable transport systems from the current hypothetical conditions and demonstrate how the future urban environments may look like and operate in the future. Section 5 analyses a series of relevant national policy implications to illustrate how urban transport system objectives can be achieved with much higher dependence on sustainable transport in selected developing countries. Section 6 concludes the paper.

\section{URBAN TRANSPORT TRENDS IN EMERGING ECONOMIES}

\subsection{Urbanization Trends}

In 2018, around 4.93 billion people live in one of the most influential thirty developing countries, representing around $66 \%$ of the world's population [20]. Among the thirty most powerful developing countries of the world, five are in Africa (Algeria, Egypt, Morocco, Nigeria, and South Africa), three are in South Asia (Bangladesh, India, Pakistan), two are in East Asia (China and Taiwan), five are in South East Asia (Indonesia, Malaysia, Philippines, Thailand, and Vietnam), two are in Eastern Europe (Russia and Ukraine), six are in Latin America (Argentina, Brazil, Colombia, Mexico, Peru, and Venezuela) and seven are in the Middle East (Iraq, Iran, Kuwait, Saudi Arabia, Turkey, Qatar, and United Arab Emirates).

All the selected countries show significant population growth rates, with increases of 1.5-4.5\% across Latin America, Africa, Asia, and the Middle East. In contrast, a few countries have encountered population decline (Russia with $-0.2 \%$ and Ukraine with $-0.3 \%$ ) and the economic reversal (Venezuela with $-3.9 \%$ ) over the last two decades. The levels of urbanization growth also vary significantly across different regions. While countries in major developing countries have similar mobility problems, they are significant features in population from 2.6 million in Qatar to 1.373 million in China, urbanization rate from $33 \%$ in India to $92 \%$ in Argentina (Table 1). Though African continent is predominantly rural, with only 30 per cent living in Nigerian urban areas in 1990, with an average annual growth rate of 4.3 per cent, it is the country with the highest rate of urbanization. In 1990, the developing economies of Latin America had the highest rate of urbanization (75\%) of any developing region. The level of urbanization in Kuwait, Qatar and the United Arab Emirates is approximating 95\% in 2018 (see Table 1). 
Table 1. Urbanization trends of the selected 30 emerging countries [20]

\begin{tabular}{|c|c|c|c|c|c|c|}
\hline & \multirow{2}{*}{$\begin{array}{l}\text { Population } \\
\text { in } 2018 \\
\text { (million) }\end{array}$} & \multirow{2}{*}{$\begin{array}{l}\text { Urban population } \\
\text { growth (annual \% } \\
\text { from } 1990 \text { to } 2018 \text { ) }\end{array}$} & \multicolumn{3}{|c|}{ Urbanization rate $(\%)$} & \multirow{2}{*}{$\begin{array}{c}\text { Estimated carbon } \\
\text { emissions (metric } \\
\text { tonnes } \mathrm{CO}_{2} \text { / person) }\end{array}$} \\
\hline & & & 1990 & 2018 & $\begin{array}{c}\text { Annual } \\
\text { change rate }\end{array}$ & \\
\hline Algeria & 40.6 & 2.5 & 54 & 72 & 1.07 & 2.8 \\
\hline Argentina & 43.8 & 1.3 & 86 & 92 & 0.25 & 4.1 \\
\hline Bangladesh & 163.5 & 3.2 & 20 & 35 & 2.09 & 0.2 \\
\hline Brazil & 202.6 & 1.3 & 74 & 86 & 0.56 & 2.3 \\
\hline China & 1373.4 & 2.6 & 28 & 57 & 2.67 & 4.5 \\
\hline Colombia & 45.7 & 1.2 & 68 & 77 & 0.46 & 1.4 \\
\hline Egypt & 94.3 & 1.8 & 41 & 44 & 0.26 & 1.9 \\
\hline India & 1311.5 & 2.3 & 26 & 33 & 0.89 & 1.1 \\
\hline Indonesia & 259.1 & 2.3 & 31 & 55 & 2.15 & 1.2 \\
\hline Iran & 79.3 & 1.7 & 58 & 74 & 0.91 & 7.2 \\
\hline Iraq & 38.2 & 3.1 & 53 & 70 & 1.06 & 3.6 \\
\hline Kuwait & 4.1 & 2.5 & 91 & 97 & 0.28 & 30.9 \\
\hline Malaysia & 31.2 & 2.2 & 50 & 74 & 1.46 & 6.7 \\
\hline Mexico & 123.7 & 1.6 & 72 & 80 & 0.39 & 4.5 \\
\hline Morocco & 35.3 & 2.1 & 49 & 61 & 0.81 & 1.2 \\
\hline Nigeria & 184.2 & 4.3 & 30 & 49 & 1.83 & 0.7 \\
\hline Pakistan & 193.2 & 2.5 & 31 & 39 & 0.85 & 0.7 \\
\hline Peru & 32.1 & 1.4 & 53 & 77 & 1.44 & 1.3 \\
\hline Philippines & 103.3 & 1.9 & 43 & 46 & 0.25 & 0.8 \\
\hline Russia & 141.9 & -0.2 & 72 & 75 & 0.15 & 12.3 \\
\hline Saudi Arabia & 32.9 & 2.3 & 65 & 83 & 1.17 & 15.7 \\
\hline South Africa & 53.8 & 2.3 & 52 & 64 & 0.77 & 10.4 \\
\hline Taiwan & 23.5 & 1.4 & 63 & 78 & 0.82 & 13.3 \\
\hline Thailand & 69.2 & 1.7 & 34 & 49 & 1.44 & 3.7 \\
\hline Turkey & 77.4 & 2.2 & 60 & 74 & 0.78 & 3.5 \\
\hline Qatar & 2.6 & 2.7 & 63 & 99 & 1.69 & 62.3 \\
\hline Ukraine & 44.8 & -0.3 & 62 & 69 & 0.33 & 7.5 \\
\hline United Arab Emirates & 9.4 & 1.7 & 61 & 86 & 1.23 & 35.5 \\
\hline Venezuela & 31.9 & 1.8 & 77 & 89 & 1.10 & 4.6 \\
\hline Vietnam & 92.7 & 2.9 & 43 & 54 & 0.85 & 1.9 \\
\hline
\end{tabular}

According to Table 1, examining $\mathrm{CO}_{2}$ per person around the most powerful thirty developing countries shows the gulf between the small populated countries responsible for the environmental disaster and that of the largely populated countries. While several small populated Gulf States (Kuwait, Qatar, and United Arab Emirates) are more than 30 tonnes per person and two Asian Giants, China and India, are on a mere 4.3 and 1.1 , respectively. Less urbanized nations such as Bangladesh and Pakistan are on an order magnitude less again - the average Bangladeshi or Pakistani people had a footprint of nearly 0.5 tonnes in 2018.

\subsection{Economic Trends}

Table 2 demonstrates a list of the major regions of the selected countries sorted by their gross domestic product (GDP) and by accounting GDP for its population (GDP per person). The list shows the World Bank's mostly 1990 and 2018 estimates.

Table 2. The Selected Regions by Total GDP and GDP per Person in 2018 [20]

\begin{tabular}{|c|c|c|c|c|c|}
\hline Rank & Continent/Region & $\begin{array}{c}\text { Total GDP } \\
\text { (US\$million) }\end{array}$ & $\begin{array}{c}\text { Total Population } \\
\text { (Million) }\end{array}$ & $\begin{array}{c}\text { GDP per } \\
\text { Person } \\
\text { (US\$million) }\end{array}$ & $\begin{array}{c}\text { Annual economic } \\
\text { growth (\%) } \\
\text { (from 1990 to 2018) }\end{array}$ \\
\hline 1 & Middle East & $2,827,038$ & 243.9 & 11,590 & 2,8 \\
\hline 2 & Latin America & $4,576,428$ & 447.9 & 9,748 & 2,2 \\
\hline 3 & East Asia & $12,593,912$ & 1396.9 & 9,199 & 8,6 \\
\hline 4 & Eastern Europe & $1,636,790$ & 186.7 & 8,776 & 1,8 \\
\hline 5 & South East Asia & $2,479,952$ & 573.6 & 4,323 & 4,8 \\
\hline 6 & Africa & $1,250,767$ & 408.2 & 3,064 & 4,1 \\
\hline 7 & South Asia & $3,176,379$ & 1668.2 & 1,904 & 7,1 \\
\hline & Average & $28,541,266$ & 4925.4 & 5,752 & 6,2 \\
\hline
\end{tabular}


As of 2018 , The selected case countries had a cumulative GDP of about $\$ 28.5$ trillion against a population of 4925 million people. The average per capita GDP in the 30 major developing countries is US $\$ 5,752$. The prospects for the selected all thirty emerging countries except Venezuela are moderately positive, with an expected growth of $0.7-8.7 \%$ [20]. East Asia has the most powerful economy (US \$ 12,6 billion) and the highest annual Growth GDP per person (\% 8.6) according to the World Bank 2018 report. India (US \$ 2,6 billion), Brazil (US \$ 2,1 billion), Russia (US \$ 1,5 billion), and Mexico (US \$ 1,2 billion) have some of the greatest powers in the world's developing countries promoted by the large gross domestic product [20].

Most of the top ten poorest countries are in South Asia and South East Asia with the majority having a per capita GDP of less than $\$ 2,000$ and $\$ 4,500$ [20]. Even though East Asia has the biggest nominal GDP and the highest average annual growth rate, certain large economies in Eastern Europe, Latin America and the Middle East are slowing down the aggregate increase for developing economies. On the other hand, the Middle East and Latin America have an average GDP per capita of 11,600 and 9,800, respectively, the highest of the seven major regions [20].

There are explicit evident differences among several Asian regions. The largest average GDP per person was in East Asia with $\$ 9,200$, whereas South Asia with an average $\$ 1,900$ has the smallest GDP per person in 2018 [20]. The urban transport development in major developing countries are managed by a relatively moderate urbanization growth (ranging from $0.15 \%$ to $29 \%$, between the years 1990 and 2018, see Table 1) and a moderate economic growth (ranging from $1.8 \%$ to $8.6 \%$ annually, see Table 2). As a result, it can be deduced that an increase in mobility demand for passenger transport, particularly for major cities in emerging economies and their surrounding urban areas could be expecting.

The proportion of private car ownership differs greatly in the selected developing countries, varying from 4 cars per thousand people in Bangladesh to 532 cars per thousand people in Qatar. The other countries with the highest relative proportion of car ownership rates are Russia, Malaysia, Taiwan and Argentina with 369, 361, 333, and 314 per thousand people, respectively [20]. South Asia had the lowest private ownership rates, accounting for nearly 3 per cent of all private cars regionally. However, Table 2 demonstrates relatively low levels of private car ownership per thousand inhabitants for many South Asian countries (4 per thousand for Bangladeshi; 18 per thousand Pakistanis, and 51 per thousand Indian), their annual economic growth between 1990 and 2018 were higher than many other emerging economies, which ranges from $4.9 \%$ (Pakistan) to $7.3 \%$ (India).

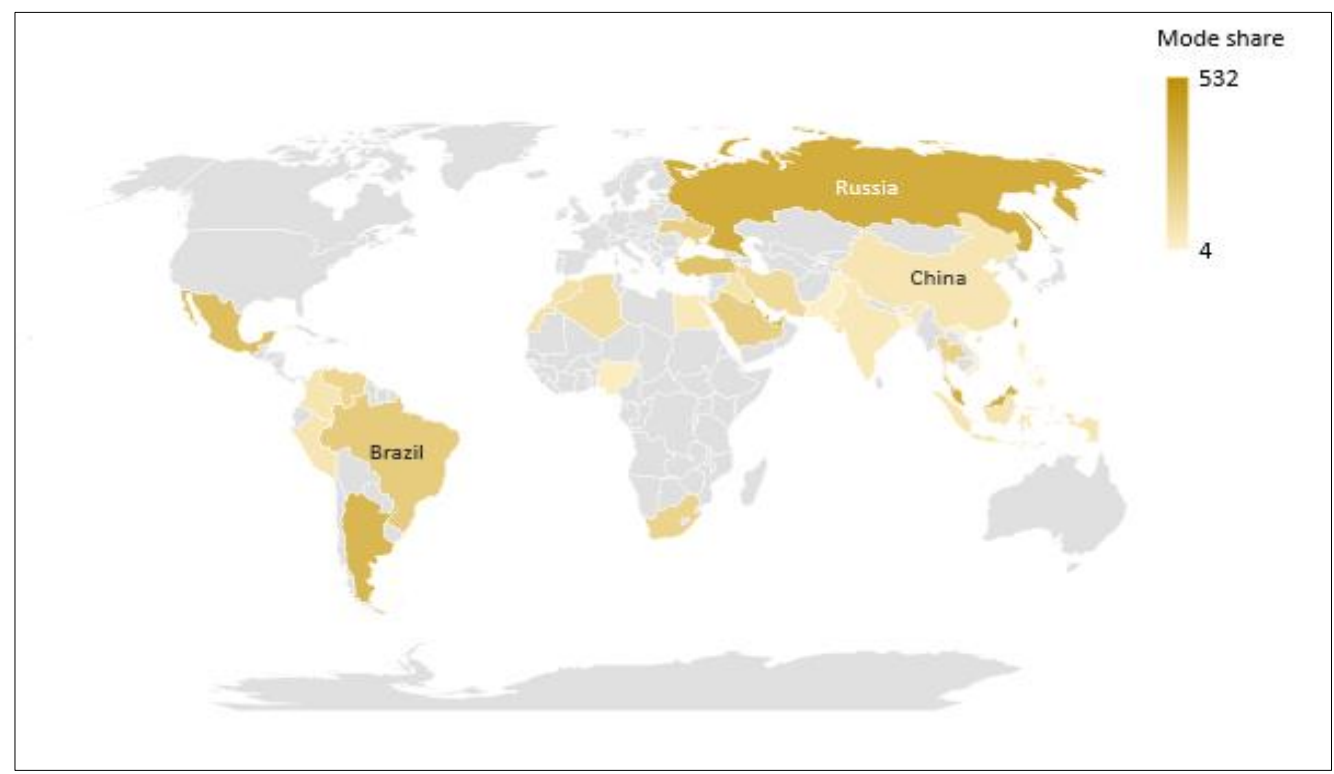

Figure 1. Private cars per 1000 people [20] 
In Africa countries, private car plays a comparatively limited role, accounting with a maximum of 7\% in Egypt, Nigeria and Morocco, but are more significant in other African countries such as Algeria (11.2 per cent) and South Africa (16.3 per cent). In contrast, in the Middle East, the number of private car ownership relative to cars high. In Kuwait, for instance, private car ownership accounts for 52.7 per cent in Kuwait, while the average share across the United Arab Emirates and Turkey are 31.3 and 25.4 per cent, respectively.

\subsection{Fast Urbanization and Car Ownership Problems}

In terms of urbanization, economic growth, and motorization trends, the selected developing countries present comparable differences in urban transport challenges. The study conducted by Vasconcellos [21] explained that the conditions of current public transport systems in many Brazilian cities and towns have remained -unchanged over the last five years, while a series of private car subsidies and incentives visibly encourage a large part of the community to use a private car. It was highlighted that civil society organizations, a supporter for sustainable urban development, has had little political influences, whereas Brazilian leaders are strongly supportive of private car and the availability gasoline prices encourage people to use a private car. Kenworthy and $\mathrm{Hu}$ [9] demonstrated how private car companies provide an undoubted backdrop for air pollution of Chinese major cities becoming less oriented about public transport. They explicated that Chinese cities would opposite their urban transport tendency through the main revival of high-quality rail transit and reviving the national infrastructures of non-motorized modes. Venter et al. [13] underlined that the national Colombian government has been developing a renowned Bus Rapid Transit (BRT) system in many cities across the country. The Colombian BRT system was determined to have yielded enormous socio-economic advantages, decreasing costs, travel times, road accidents, traffic congestion through the competition between paratransit and motorcycles with official public transport, but the financial solvency of public transport operators have remained insufficient. Bhattacharya et al. [12] illustrated that inadequate Indian transport conditions associated with national economic growth efforts and pose grave consequences to the sustainable growth of many Indian urban areas. Major obstacles in Indonesian urban transport development was elucidated by Suliso et al. [22] that a capital-intensive road construction focused on easing congestion in/around urban areas is limited, and financial resources have constituted a concern even with short-term congestion mitigation rather than future visioning. Soltani and Hoseini [23] highlighted that the challenges for the sustainable development of Iranian urban landscape are vast oil reserves. There are very limited developments regarding the regulation of land uses in the landscapes of the major cities. They are underlined to have often covered by informal tracts, inadequate housing and primitive road transport networks which makes road congestion extremely intolerable in the country. Therefore, air pollution problems in big cities, such as; Tehran, Mashhad and Isfahan pose a serious threat to public health. Contrary to sustainable development, Iranian urban areas are car-oriented environments because fuel is so affordable. A longitudinal study of the transport systems available in Mexican cities by Connolly [24] focused on spatial inequalities caused by Mexican cities progressively geared towards private car use by a minority. Although the study expressed some advances in non-motorized mobility infrastructure in particularly high-income places and touristic locations of Mexican cities, profound scepticism regarding the effectiveness of recent mobility policies for designing sustainable urban transport systems are expresses. For example, new Mexican highway bus systems are stressed to be less flexible and more expensive than the previous system; on the other hand, the development of highcapacity transit for the outskirts has been troubled with technical and financial challenges. Therefore, the Mexican local governments are devoted to the construction of more and more urban highways. As for Nigeria, Stucki [5] reports that the most obvious challenge of Nigerian urban mobility policy is a lack of local technical capacity to manage non-compliant, yet administratively powerful providers. This struggle happens amidst high demand increase for private-sector transport services, constrained capacity of riders to compensate for services, quick expansion at the urban fringe, and great motorization rates regularly involving second-hand cars imported from foreign countries. B1yık [3] highlighted that Turkish transportation policies do not usually address the needs of the population 
growth, although the political agenda of all Turkish cities are highly related to urban transport issues. Responding to increased mobility demand, radical rearrangement and modernization of public transport facilities, development of walking and cycling transport systems and effective control of motorization are required. Decisionmakers are less reluctant to improve bus services and non-motorization use. On the contrary, the national and local governments effort to rebuild huge investments in an urban road project, which push more people to travel by private cars. To illustrate both similarities and differences in the features of urban transport strategies in South African cities, Dewar and Todeschini [14] indicated the disciplines of spatial and transportation planning for South African cities. South African cities are pronounced to still be non-sustainable, although it has been many years since the achievement of democracy and majority rule. While there is no significant innovation in the new South African urban transport systems, the authors state that it is not possible to achieve radical improvements to sustainable urban futures. As the circumstances of economic factors and inequality become unstable, the burden imposed by the structure and form of the South African cities is harshly damaging to family budgets and occasions. To better understand the urban transport problems and its effects in Vietnam, Dapice et al. [10] highlighted that the major Vietnamese cities have been harassed with traffic congestion and public health problems due to massive migration from rural to urban areas. This is essential because districts of Vietnam cities are quite far away from each other, and secondly, the design quality of city roads is not well-enough to provide such a sustainable service. A massive part of the public in major urban areas have adopted motorcycles as a solution to road traffic congestion problems, but motorcycle users now cause significant effects on congestion and adverse air quality.

\section{A-S-I APPROACH IN THE CREATION OF FUTURE VISIONS}

The development of sustainable transport systems can be achieved through the Avoid-Shift-Improve (ASI) approach. This approach is broadly adopted to deal with the challenges of urban transport [25]. The traditional worldwide approaches for sustainable transport development are divided into three sections.

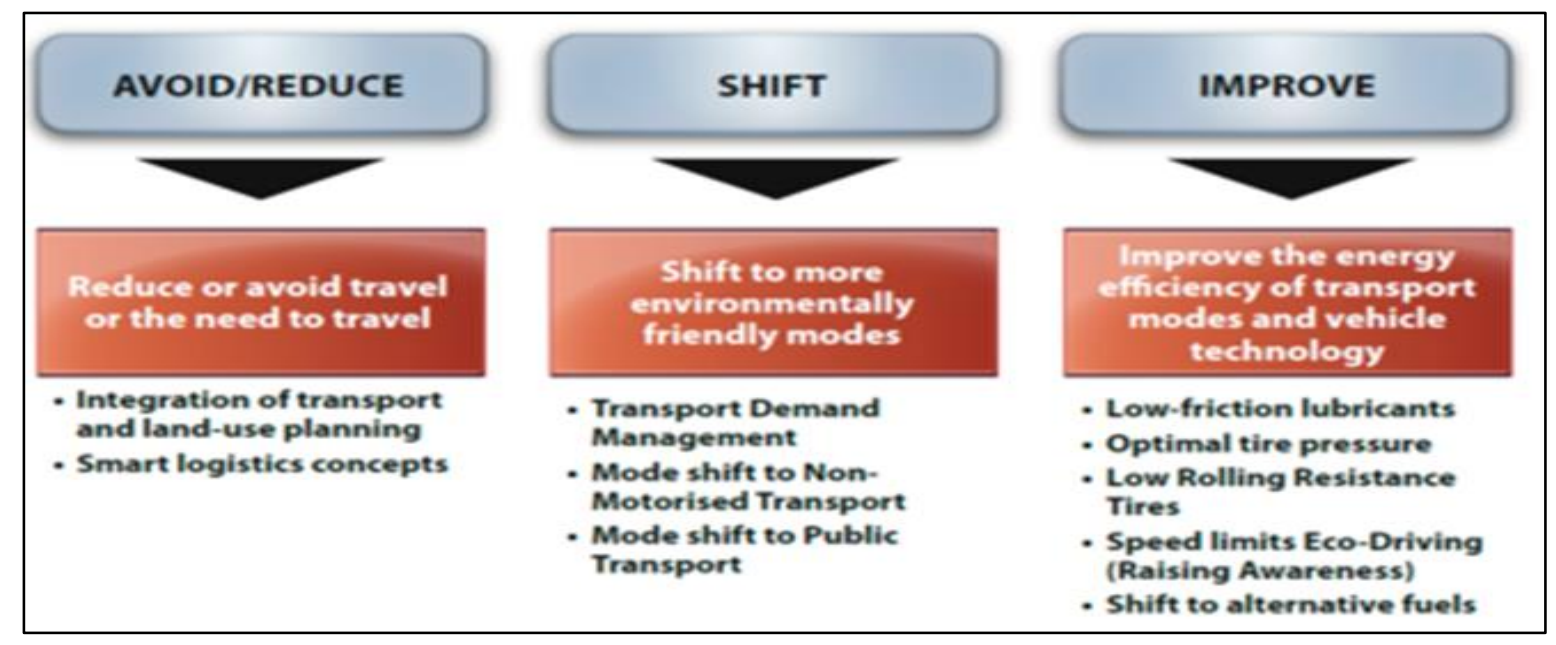

Figure 2. Directions of Sustainable Urban Transport System [26]

The "Avoid" component seeks to diminish travel demand through telecommuting, online shopping, and improving local access to jobs, goods, and services. Smarter planning focused on designing dense urban environments has assisted in decreasing the demand for motorised trips. The "Shift" component seeks to contribute to the efficiency of urban space/infrastructure and reduces fuel consumption by shifting modes of travel from private car to public transport and non-motorised alternatives. The "Improve" component seeks to reduce the adverse effects of private vehicles by improving the environmental performance of transport systems and management technologies (see Figure 2). 
The hypothetical developing urban areas and its alternative appearances in the framework of A-S-I approaches were firstly created, as demonstrated in Figure 3. All approaches demonstrate for parts of an imaginary urban area of a typical developing country, showing a high dependency on sustainable transport systems, which is improved, and with provision for a limited number of private cars. Specific locations are designed to consist of a residential area, an area close to a busy university campus, and part of the city centre. These practices are clearly unique from many perspectives including the design of land-use patterns, mode-share and transport infrastructure. Therefore, each of these three locations in the hypothetical urban areas during 2018 is not intended to represent one specific city (or region) of the developing country - indeed many examples of such locations exist in different emerging economies with familiar traffic requirements.

The final stage of this work was operationalised through a series of online interview between January 2019 and April 2019. The online interview mostly aimed to attract relatively senior participants from the local and national governments from many developing countries.

The recruitment letter was sent to approximately 141 participants from the e-mail lists obtained from local and national transport departments of the selected thirty countries. A total of 28 people agreed to participate, and they were given a choice to provide their contact information for a possible online interview, but 53\% of these participants (15 people from 8 different countries) involved in the worldwide sustainable development exercises through semi-structured interviews. Each international policymaker was provided with samples of generic illustrations for specific visions (such as those presented in Figure 3). Further clarification was provided giving extended vision narratives for each vision.

\section{VISIONS FOR EMERGING URBAN AREAS}

Avoid Vision deliberates future situations where a modification from the present has been presented through a wish on the society's share to decrease the number of daily journeys in urban areas. Technological innovations are the most improved one, which allows to decrease possible 
accidents in road transportation and to develop a more environmentally friendly transportation system. Although the influence of growing petrol prices on different features of urban form is likely hard to forecast, higher petrol price would be expected to increase employment densities thus leading to denser and mixed-use urban areas. However, the changes in urban form tend to happen very slowly because increases in urban density are constrained by local land use strategies. High parking prices and cycling awareness events encourage people to utilise cycling.

Shift Vision has been enforced upon society by inspiring a much wider range of people to prefer walking and cycling systems. Local administrations would receive funding for making cycling or walking safer and more attractive, which can be achieved by implementing traffic calming measures. Wider spaces are assigned to cyclists and pedestrians. Housing unaffordability in the central core of cities causes the population to live or work suburbs in the middle and outer rings of the city. The expansion of new public transport systems would make social and business settlement formation on the outer parts of the urban areas more appealing. Local governments are preserving parks or forest lands from quickly urban spreading towards the outer parts of the urban environments. The public would hardly experience a low quality of life on urban fringes due to restructuring roads for non-motorized users, particularly in residential areas.

Improve Vision expresses another primary travel technique by external constraints - in this case, a fuel catastrophe - so the widespread and affordable public transport systems suggest more energy efficient vehicle technology for the entire society. A significant proportion of technological development consists of innovations regarding the improvement of fuel performance and economy. New vehicles would operate on renewable energy that produces fewer emissions, or on electrical power, which can be considered as a sustainable source, where the source is green. Decision makers should focus delicately on overcoming the difficulty of procuring energy by investing in public transportation systems and by increasing awareness of the community about sustainable energy trends. The proposed improvements on public transportation systems eventually make commuting happen in a friendlier environment and turn it into less stressful and more productive time.

\section{POLICY SUGGESTIONS}

This paper revised the barriers of the sustainable transport system as well as policy measures for developing countries. The objective of the improvement of a sustainable transport system is to evacuate the unsustainability factors, thus boosting workability. The policy measures of the future transport systems are: (1) encourage the use of non-motorized transport modes; (2) simultaneously driving forward urban and sustainable transport development; (3) control the private car demand to address road congestion; and (4) maintain the public-transport-oriented transport system. Also, the policy measures for realizing a sustainable transport system presented herein implementing effective demand control policies based on the features of motorcycles and strong demand-containing policies such as imposing a congested-traffic tax, parking control policy, pricing policies, strengthen the linkage with non-motorized modes such as bikes and traffic management.

\subsection{Encourage The use of Non-Motorized Transport Modes}

Several developing urban areas, such as Bogotá, Rio de Janeiro, São Paulo and Shanghai are recently investing important amounts in walking and cycling infrastructure and these active transport modes are being formally recognized as a crucial priority in new transport plans. In China, cycling sharing programs are being presented to revive the cycling tradition. It appears that attitudes may be gradually changing among rising numbers of decision-makers in some urban areas and that non-motorized transport is being recognized as important modes. 
"Many research consuls and conferences have made significant differences in the way the municipalities view the difference between companies and bicycle transport. Companies in Brazil have recently been organizing marathon to raise awareness of a healthy lifestyle. Many municipalities are becoming more enthusiastic about bicycle access and the municipalities in some coastal towns have also encouraged people to participate in various cycling competitions. Likewise, people can be encouraged to use a bicycle or public transportation for daily working journeys. This can also reduce carbon emissions. In addition, companies may not have to allocate special vehicles or provide service access for their employees"' (National policy maker, Brazil, female, 46-55).

"The ministry of transport does not want to be held responsible for walking and cycling or any other alternative modes that do not link with railway transport systems. There are problems about sharing political responsibilities and working coordinately with the Ministry of Environment"' (National policy maker, Egypt, male, 26-35).

\subsection{Simultaneously Drive Forward Transport Development}

Sustainable transport systems usually need high densities and mixed uses to be practically and financially feasible. Nevertheless, there are many complications in the association between transport and land-use. The evidence to date shows that there is no obvious sustainable urban form, but uncontrolled low-density diffusion is never the most appropriate form. In most developing urban area contexts, land use intensification regularly occurs in the absence of land use controls and strict enforcement to avoid sprawl appear to be unlikely.

"The implementation of macro and micro urban planning in Malaysia has huge challenges and inconstancies. Although macro planning is designed for the $10-15$ years, urban development is growing uncontrollably and encourages rapid investments in road systems. Therefore, people are also quickly shifting to buy and use a private car. This makes it very difficult for public transport to compete with car use. Therefore, the Ministry of Public Works and People's Housing can prevent the green areas from travelling outside the city and ensure safety in new social areas" (National policy maker, Malaysia male, 56-65).

\subsection{Control The Private Car Demand to Address Road Congestion}

Road pricing and taxation schemes have been implemented in just a handful of countries. In some parts of Latin America and Asia, there are some examples of small-scale pedestrianization schemes in historic or commercial centres can be found. For example, cordon pricing has been presented in Tehran, where drivers are compulsory to pay an annual access fee. Although the pricing scheme is seen to have decreased traffic congestion levels within the cordon, its citywide effect has been limited. Bangkok made efforts to limit all newly recorded cars to use especially in non-rush hours. In Guangzhou, the operation of commercial vehicles has been restricted in unprecedentedly detailed ways. In Latin America, major cities including Mexico City, Santiago, São Paulo, and Bogotá have implemented the similar measures for some time.

"Congestion charge might be recently applicable in major Iranian cities and could be the solution of issues we encounter. Such as studies to reduce vehicles from traffic. But the actual implementation strategies required for preventing traffic congestion is not the push factors such as increasing parking fees or traffic congestion charges. There must be pulled factors, systems to promote public transport and encourage people to use more of these systems" (National policy maker, Iran, male, 36-45). 


\subsection{Maintain The Public-Transport-Oriented Transport System}

Increased investments in all types of public transport promise to the economic growth of developing cities. Metro systems are generally the most expensive form of public transport in terms of construction and operation and this system is being well-developed in some major cities of the emerging economies (e.g., Brazil, Russia, India and China). Chinese cities have been at the forefront in this respect aided by a strong and growing economy. However, in most other developing countries, metro systems are not usually affordable, and they are often expensive. In addition to high fees, other issues that urban-rail systems suffer is their week integration with other transport modes. In addition to high costs, a problem that rail systems suffer is their poor integration with other modes and operators. To accomplish integration and change existing model-based planning approaches, strategic and comprehensive public transport masterplans are required.

"In Mexico, the Ministry of Environment and Natural Resources is not a well-established institution like the Ministry of Communications and Transportation, which could spend 25-30 billion Mex\$ on new road construction, every year. However, if a budget of 100 thousand Mex\$ has been allocated for the use of non-motorized vehicles, a 10\% increase in the use of these systems could be provided. But the most fundamental problem is that there are not any group or organization represents the rights of cyclists, pedestrians and public transport users. Local governments do not want to risk the loss of car driver votes for supporting sustainable transport systems. They are selected for 6 years and they do not want to risk people's lifestyle, especially by limiting the freedom of car users. The top officials of local governments are generally not those who have expertise in transportation" (National policy maker, Mexico, 56-65).

In many developing cities, the current road-based public transport services do not assist the mobility requirements of the population sufficiently. Formal bus services are not often reliable, convenient, comfortable, or even not safer. Informal paratransit services, while providing assistance including the on-demand movement for the transit-dependent carry serious prices, such as increased traffic congestion, air and noise pollution, and traffic accidents.

"Travellers use mini-bus services (often called as dolmus) at any places they want and get off where they want to leave. Minibuses are therefore extremely convenient because people do not have to walk through the nearest bus stops around 800-900 meters. In Kayseri, the local transport council and the governor's office brought together two or three full-fledged owners to make the public bus owner in their own city" (Local policy maker, Turkey, female, 46-55).

\section{DISCUSSION AND CONCLUSION}

It is worth noting that cities in developing countries encounter rapid car usage and urban expansion growth, mainly caused by economic expansion. Moving the existing growth trajectory toward satisfying sustainable transportation needs a radical shift and can be suggested specific strategies to implement various effective actions.

To implement the policy measures a comprehensive approach needs to be coordinated among different authorities and institutions. It was found that the various processes associated with the approaches to future transport planning might be implemented successfully using the following: there is a need for satisfactory non-motorized transport implementation strategies and policies across all spheres of government; ensuring coordination of transportation and urban planning practices; the number of examples of small-scale active transportation schemes in historical or commercial centres could be increased by implementing both push and pull measures; and increasing investments in type of more sustainable forms allows these systems to address more individuals in developing cities. 
This paper has covered a limited portion of the 1,000-mile journey in sustainable transport in the developing world. A fundamental argument of sustainability issues and illustrative best transport practice examples can be critical to creating a joint agenda in the developing region capitalizes on and potentiates these experiences. While some political proposals have been put forward, every developing country needs diversified policies in the development of sustainable transport visions. Certainly, such futures and political developments would comprise a large degree of agreement that such a vision is achievable, that the existing transportation barriers are real, and that essential approaches to tackling them are crucial. However, it is vital to highlight that if the consistency of such drastically different futures is not established, then it is less likely that such changes will be achieved in the developing world.

\section{REFERENCES}

[1] Linnenluecke, M.K., Verreynne, M.L., de Villiers Scheepers, M.J. and Venter, C., 2017. A review of collaborative planning approaches for transformative change towards a sustainable future. Journal of cleaner production, 142, pp.3212-3224.

[2] Nieuwenhuis $\mathrm{P}$, Vergragt $\mathrm{P}$, Wells $\mathrm{P}$. The business of sustainable mobility: from vision to reality. Routledge; 2017 Sep 8.

[3] Biyık C. Smart cities in Turkey: Approaches, advances and applications with greater consideration for future urban transport development. Energies. 2019 Jan;12(12):2308.

[4] Biyık C. Is a 30\% Reduction in Emissions by Changing Transport Patterns in Ankara Feasible? International Journal of Environmental Science and Development. 2015 Jan;6(1).

[5] Stucki M. Policies for Sustainable Accessibility and Mobility in Urban Areas of Africa. Working Paper. Washington, DC: World Bank Group; 2015.

[6] Venter C, Jennings G, Hidalgo D, Valderrama Pineda AF. The equity impacts of bus rapid transit: A review of the evidence and implications for sustainable transport. International Journal of Sustainable Transportation. 2018 Feb 7;12(2):140-52.

[7] Pucher J, Korattyswaropam N, Mittal N, Ittyerah N. Urban transport crisis in India. Transport Policy. 2005 May 1;12(3):185-98.

[8] Jain M, Korzhenevych A, Hecht R. Determinants of commuting patterns in a rural-urban megaregion of India. Transport Policy. 2018 Sep 30; 68:98-106.

[9] Kenworthy J, Hu G. Transport and urban form in Chinese cities: an international comparative and policy perspective with implications for sustainable urban transport in China. disP-The Planning Review. 2002 Jan 1;38(151):4-14.

[10] Dapice D, Gomez-Ibanez JA, Nguyen XT. Ho Chi Minh City: the challenges of growth. United Nations Development Programme in Vietnam; 2009.

[11] Oh JJ, Sinha KC. Self-financing and distance-based highway pricing scheme: State highway system perspective. Journal of Infrastructure Systems. 2010 Oct 9;17(3):95-106.

[12] Bhattacharya S, Rathi S, Patro SA, Tepa N. Reconceptualising smart cities: a reference framework for India. CSTEP-Report-2015-03. 2015 Sep 2. 
[13] Venter C, Jennings G, Hidalgo D, Valderrama Pineda AF. The equity impacts of bus rapid transit: A review of the evidence and implications for sustainable transport. International Journal of Sustainable Transportation. 2018 Feb 7;12(2):140-52.

[14] Dewar D, Todeschini F. Rethinking urban transport after modernism: lessons from South Africa. Routledge; 2017 Jul 5.

[15] Stead D, Pojani D. The urban transport crisis in emerging economies: A comparative overview. InThe Urban Transport Crisis in Emerging Economies 2017 (pp. 283-295). Springer, Cham.

[16] Inayatullah S. City futures in transformation: Emerging issues and case studies. Futures. 2011 Sep $1 ; 43(7): 654-61$.

[17] Jarrett J, Woodcock J, Griffiths UK, Chalabi Z, Edwards P, Roberts I, Haines A. Effect of increasing active travel in urban England and Wales on costs to the National Health Service. The Lancet. 2012 Jun 9;379(9832):2198-205.

[18] Iwaniec D, Wiek A. Advancing sustainability visioning practice in planning-The general plan update in Phoenix, Arizona. Planning Practice \& Research. 2014 Oct 20;29(5):543-68.

[19] Järvi T, Tuominen A, Tapio P, Varho V. A transport policy tool for reduction of CO2 emissions in Finland-Visions, scenarios and pathways using pluralistic backcasting method. Transportation Research Procedia. 2015 Jan 1; 11:185-98.

[20] The World Bank. World Urbanization Prospects: The 2018 Revision-Highlights. UN. 2018.

[21] Vasconcellos EA. Urban development and traffic accidents in Brazil. Accident Analysis \& Prevention. 1999 Jul 1;31(4):319-28.

[22] Susilo YO, TJOEWONO TB, Santosa W, Parikesit D. A reflection of motorization and public transport in Jakarta metropolitan area. Journal of the Eastern Asia Society for Transportation Studies. 2007; 7:299-314.

[23] Soltani A, Hoseini SH. An analysis of the connection between built environment, physical activity and health: comparing three urban neighbourhoods from Shiraz, Iran. International Journal of Urban Sciences. 2014 Jan 2;18(1):19-30.

[24] Connolly P. Mexico City: our common future? Environment and Urbanization. 1999 Apr;11(1):53-78.

[25] Wright L, Fulton L. Climate change mitigation and transport in developing nations. Transport Reviews. 2005 Nov 1;25(6):691-717.

[26] Deutsche Gesellschaft für Internationale Zusammenarbeit (giz) GmbH. (n.d.). Sustainable Urban Transport: Avoid-Shift-Improve (A-S-I). From Bridging the gap: www.transport2020.org/file/sutporg-asi-factsheet.pdf. 2015 